\title{
1 FAST GRIP FORCE ADAPTATION TO FRICTION RELIES ON LOCALIZED 2 FINGERPAD STRAINS
}

3 Félicien Schiltz ${ }^{1,2, *}$, Benoit P. Delhaye ${ }^{1,2,{ }^{*}}$, Frédéric Crevecoeur ${ }^{1,2}$, Jean-Louis Thonnard ${ }^{1,2}$ \& Philippe 4 Lefèvre ${ }^{1,2}$.

$5 \quad{ }^{1}$ Institute of Neuroscience, Université catholique de Louvain, Brussels, Belgium

6 Institute of Information and Communication Technologies, Electronics and Applied Mathematics, 7 Université catholique de Louvain, Louvain-la-Neuve, Belgium

* co-first authors.

\section{ACKNOWLEDGMENTS}

The authors thank Allan Barrea, François Wielant and Arsalis for their help in the development of the device. 


\section{ABSTRACT}

Humans can quickly adjust their grip force to a change in friction at the object-skin interface during dexterous manipulation in a precision grip. To perform this adjustment, they rely on the feedback of the mechanoreceptive afferents innervating the fingertip skin. Because these tactile afferents encode information related to skin deformation, the nature of the feedback signaling a change in friction must somehow originate from a difference in the way the skin deforms when manipulating objects of different frictions. To better characterize the origin of the underlying sensory events, we asked human participants to perform a grip-lifting task with a manipulandum equipped with an optical imaging system. This system enabled to monitor fingertip skin strains through transparent plates of glass that had different levels of friction. We observed that, following an unexpected change in friction, participants adapted their grip force within $370 \mathrm{~ms}$ after contact with the surface. By comparing the deformation patterns when unexpectedly switching from a high to a low friction condition, we found a significant increase in skin deformation inside the contact area arising over $100 \mathrm{~ms}$ before the motor response, during the loading phase, suggesting that local and partial deformation patterns prior to lift-off are used in the nervous system to adjust the grip force as a function of the frictional condition.

\section{INTRODUCTION}

In a seminal paper in the 80 s, Johansson and Westling described how efficiently human participants handle objects of different textures and friction (Johansson and Westling, 1984). They observed that when lifting objects, humans scaled their grip force (GF) to the frictional properties of the surface, such that an object with a slippery surface was gripped more firmly than one with a sticky surface. Moreover, it was found that a change in the frictional properties of the object from one trial to the next elicited a GF adaptation that was observable only $100 \mathrm{~ms}$ after contact with the surface. Such adaptation was cancelled under local anesthesia, underlining the essential role of afferent feedback (Westling and Johansson, 1987; Nowak et al., 2001; Augurelle et al., 2003; Witney et al., 2004). A rapid feedback loop is thus able to take into account tactile afferent information about the surface efficiently (Johansson and Flanagan, 2009; Delhaye et al., 2018).

However, the mechanisms underlying such a feedback loop remain unknown. Indeed, since the surfaces used in the aforementioned paper (Johansson and Westling, 1984) had very different textures, it is not clear whether the feedback provided by the afferents was related to the topography of the material, thereby quickly eliciting the recall of a motor memory related to the surface, or if the feedback was directly related to friction, such that the motor system could scale the GF accordingly. Notably, it was later demonstrated that human are able to adapt to changes in friction (Birznieks et al., 1998), even those that are not directly associated with a change in texture (Cadoret and Smith, 1996). In this study, different textures and coatings were used to show that humans adjust the level of GF to the coefficient of friction and not to the texture when lifting objects. These results suggest that the skin deformation during each lifting movement can be used to scale the grip force without necessarily requiring a full slip event.

The possibility that humans adjust their grip force quickly based on an estimate of friction is supported by recent imaging studies of fingertip deformation during loading. We and others have shown that localized partial slips take place at the object-finger interface during tangential loading (Levesque, 2002; Tada et al., 2006; André et al., 2011; Delhaye et al., 2014). Partial slips are associated with substantial skin deformation in the contact area (Delhaye et al., 2016) that trigger a strong afferent responses (Delhaye et al., 2021a), and may therefore signal an impending slip. Importantly, reducing friction accelerates the progress of partial slips and leads to an earlier 
discharge of the tactile afferents, which can potentially inform the central nervous system about the upcoming contact instability (Khamis et al., 2014; Delhaye et al., 2021a). Moreover, the perception of tactile slip seems to be induced by skin deformations associated to partial slip, since it is perceived before full slippage and is impeded when the amount of strains is diminished by applying a coating that reduces friction (Barrea et al., 2018). Furthermore, generating artificial skin strains at the contact interface with the object during lifting also lead to an increase in GF (Farajian et al., 2020).

Taken together, the aforementioned findings lead us to hypothesize that partial slip, or the associated skin deformations, are a sufficient sensory signal to adjust the GF to the friction condition during active manipulation. To test this hypothesis, we sought to describe and quantify where and when skin deformation associated to partial slip take place following an unexpected change of friction, and if those allow participants to adapt their GF to a change in friction that is not associated with a change in texture. To this end, we asked human participants to repeatedly grip and lift a manipulandum, while the friction was changed unbeknownst to the participant (Fig 1A-B). We found that participants adjusted the GF to a change in friction only $114 \mathrm{~ms}$ after liftoff (370ms after contact was made with the surface), suggesting that most of the sensory information about the friction change was available before the object started moving. To further understand the mechanisms underlying such adjustments, we imaged, at the same time, the contact area between the index finger and the object. We used those images to track the skin strains resulting from partial slip (Fig $1 \mathrm{~F}-\mathrm{G})$, and reveal a localized strain contrast after friction changes very early in the trial, i.e. before liftoff. Our findings thus support the hypothesis that humans make use of localized strain patterns to adjust the GF to unexpected changes in friction.

\section{RESULTS}

Participants performed a series of grip and lift trials using a custom-made manipulandum held in a precision grip (Fig 1A). Following an auditory cue, they were instructed to grip and lift the object vertically to reach a target (movement, "Mvt1" in Fig 1D), and then hold it stationary for one second (static phase, "SP1"). This task was followed by three point-to-point movements (Mvt2- 4, and SP2-3, also paced by auditory cues, not analyzed here). After each experimental block consisting of five trials, the participants were asked to sit on a chair with their back turned away to the experimental set-up, and the experimenter quickly interchanged the surfaces without the participants noticing (Fig 1B). Two sets of glass plates having different levels of friction were used (see Methods). We defined the first trial following a surface change as a "catch trial", since it included an unexpected change in friction, and the other four trials were called "normal trials". The first two blocks were considered to be "training blocks" as the participants' GFs decreased significantly during those for all participants and were thus excluded from the data analysis (Fig 1C).

The manipulandum was equipped with force sensors that allowed us to monitor the GF and the load force (LF, acting vertically and due to the object weight and inertia). A typical point-to-point movement was accompanied by two LF peaks, related to the acceleration and deceleration phases of the movement (Fig 1D). Note that each upward LF peak was paired with a GF peak. We synchronized all trials at the instant of the first LF peak. During the static phases, LF remained fairly constant $(2.2 \mathrm{~N}$, the object's weight) as did GF. 
bioRxiv preprint doi: https://doi.org/10.1101/2021.07.20.452911; this version posted July 20, 2021. The copyright holder for this preprint (which was not certified by peer review) is the author/funder, who has granted bioRxiv a license to display the preprint in perpetuity. It is made available under aCC-BY 4.0 International license.

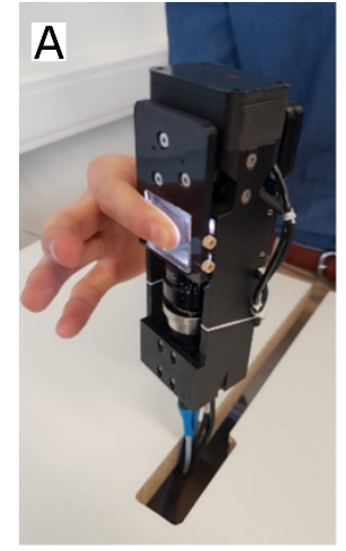

C
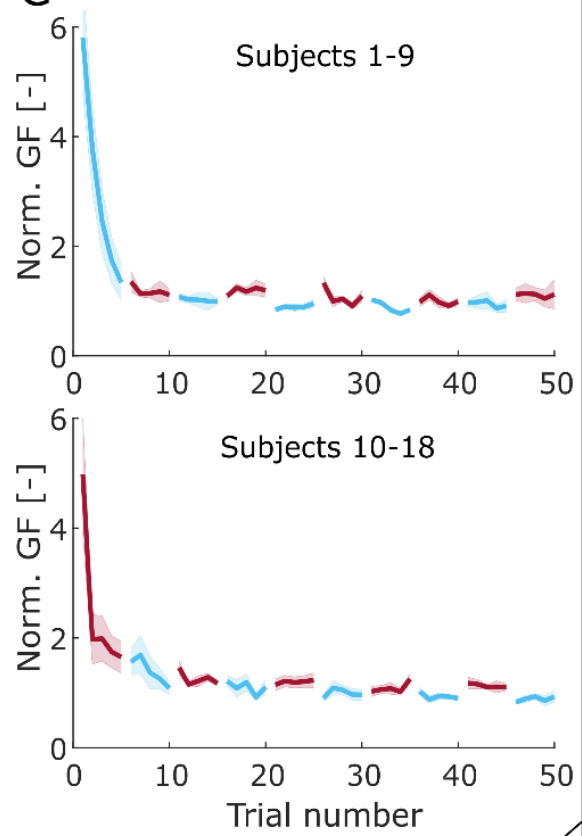

Blocs:

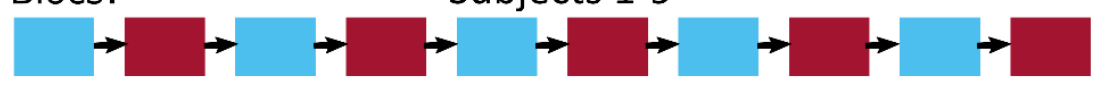

Subjects $10-18$

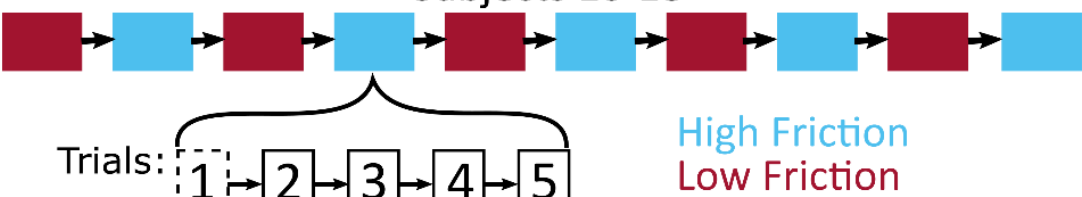
\begin{tabular}{c:cc}
\hline CATCH & NORMAL \\
\hdashline
\end{tabular}
$\mathrm{E}$

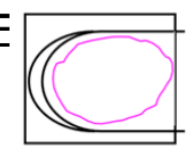

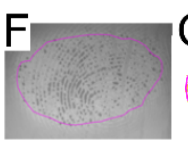
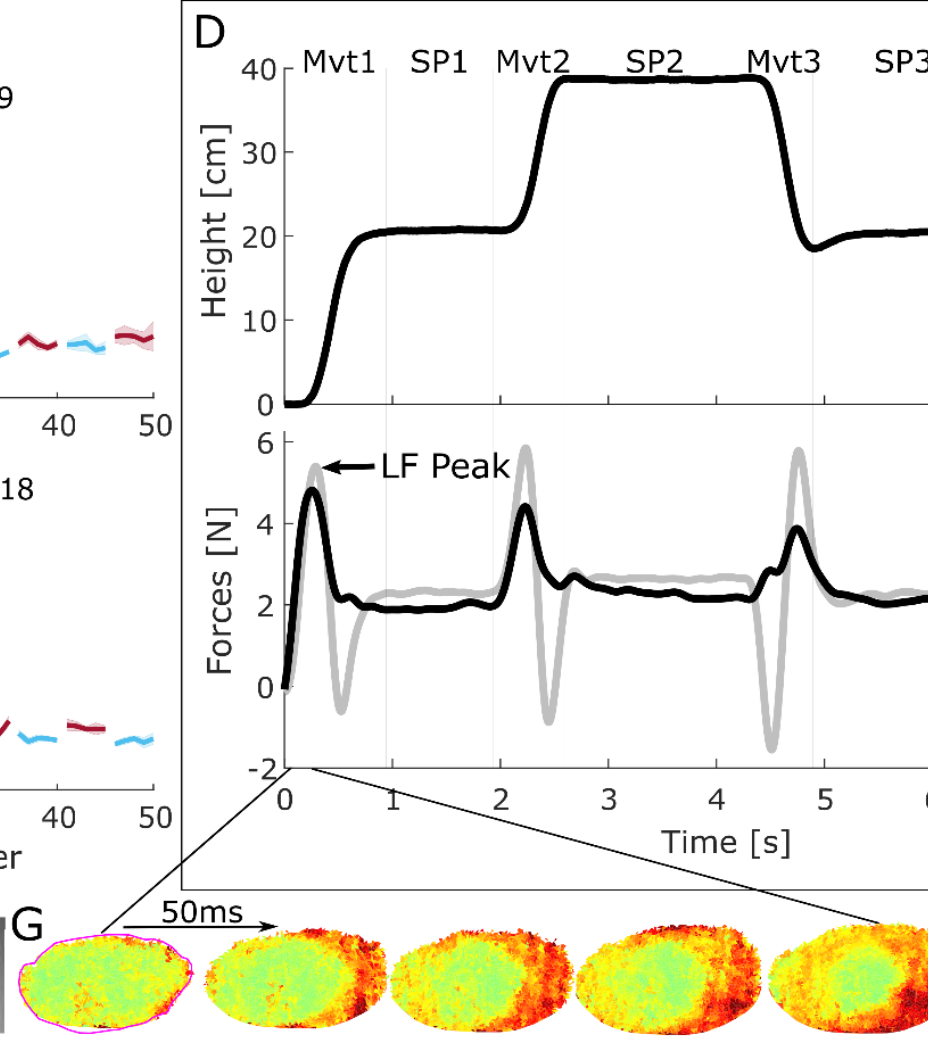

Mvt4
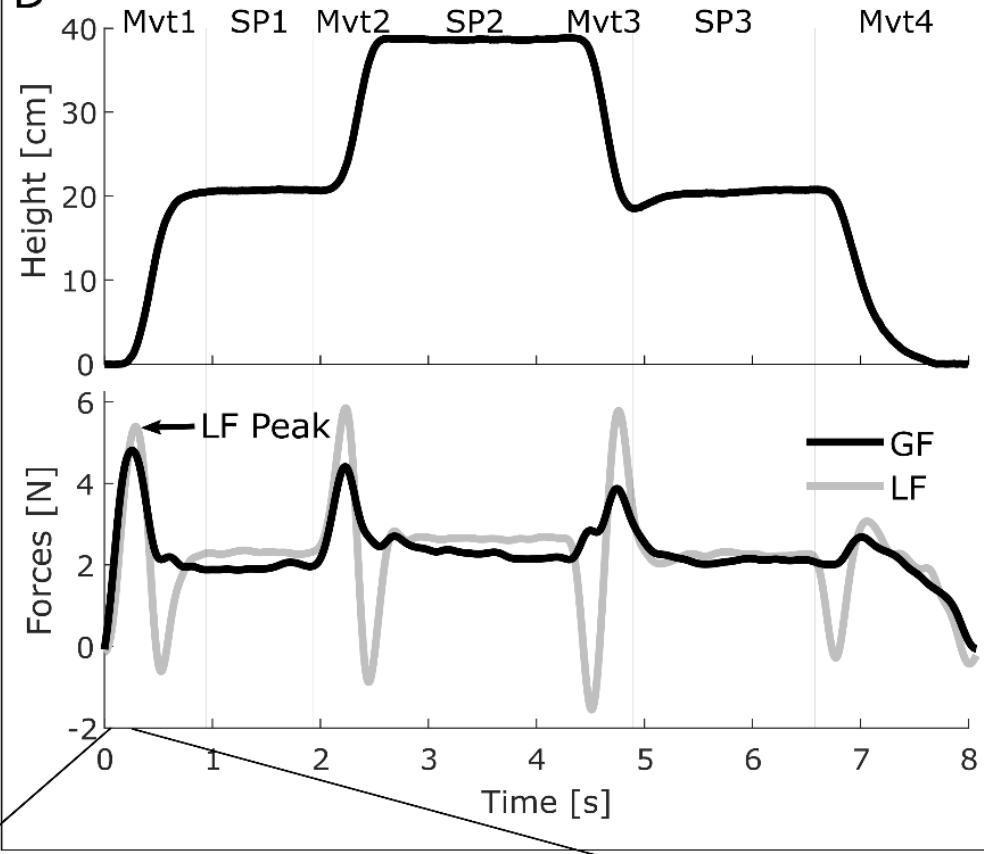

Figure 1: Experimental setup, experimental procedure, and typical trial. A| Participants held the manipulandum in a precision grip with both fingers applied on transparent glass plates. The device includes sensors allowing the measurement of the forces applied by both fingers as well as an imaging system allowing the recording of the index fingertip skin. B Participants performed ten blocks of five trials. Transparent plates with high and low friction properties were interchanged between each block. Half of the participants started with the high friction material. The first trial of each block is called "CATCH" trial, as opposed to "NORMAL" trials. Cl Group mean of the GF of the first SP for participants who started with the high friction material for the top graph and for participants who started with the low friction material for the bottom one. GF is normalized according to the procedure described in Methods. The shaded areas show the standard error of the mean. D| Evolution of the vertical position of the manipulandum and the forces applied during a typical trial. It consists of four fast movements (Mvt) with static phases (SP) in-between. Note that the second LF peak of each movement is due to the participant having to slow down the manipulandum because of the inertia of the system. The LF during the second static phase is slightly higher due to a larger portion of the cable being positioned under the device at this height. El Position of the index finger and area of contact with the glass. All strains in this study are displayed as if they were observed through the glass during the manipulation. The distal side is on the left. The pink curve delimits the contact area. Fl Typical image. Only the index finger was monitored. G| Heat maps of the norm of the skin strain rates obtained from a pair of consecutive images, as described in (Delhaye et al. 2016). This sequence shows deformations during the first $200 \mathrm{~ms}$ of a typical first movement (Mvt1 in panel C). Strains are observed at the periphery of the contact area. The central stuck zone remains undeformed. 
The index fingertip contact with the object's surface was monitored through the glass plates using a high-speed, high-resolution camera (Fig 1E-F). Image processing techniques allowed us to track fingerprint movements and evaluate surface skin strains during the lift movement (Fig 1G, (Delhaye et al., 2014, 2016), see Methods). The rate of change of skin strains resulting from LF increase during the lift of the manipulandum were observed at the periphery of the contact area (Fig 1G). In most trials, the center of the fingertip remained stuck and non-deformed, except when full slip was reached ( 87 times out of 633 , or equivalently $14 \%$ of trials). The contact area was an approximately ellipsoidal shape and increased over time following a logarithmic increase consistent with previous observations (André et al., 2011). On average, the contact area reached $85 \%$ of its maximum value $200 \mathrm{~ms}$ after the time of contact and had usually reached its maximum value $340 \mathrm{~ms}$ after initial contact (value reached: $94.4 \pm 5 \%$ of the maximum value, mean $\pm s t d$ ). This time corresponded to an average of $30 \mathrm{~ms}$ prior to liftoff.

\section{Consistent difference in friction between smooth transparent materials}

First, we verified that the two materials showed a consistent difference in their coefficient of friction. To that end, the friction between the fingertips, index and thumb, and the two sets of plates was measured at the end of the experiment to reduce potential cues about the different materials that could have been used during the manipulation task. Note that all participants except three reported that they did not notice that different materials were used. Following ((Barrea et al., 2016), see Methods), we characterized the coefficient of friction over a range of GFs relevant to our experiment (see Fig 2). The data were obtained for both fingers of all participants (and are reported in Supp Fig 1 for the index and Supp Fig 2 for the thumb) and fit with a negative power law. We observed that the coefficient of friction of the low friction glass remained lower than the one of the high friction glass across all levels of normal force tested, as shown in Fig 2A for a typical participant. From the fits obtained for each participant, we summarized the coefficient of friction by a single value, being the average coefficient of friction over the range of 1 to $5 \mathrm{~N}$ (which spans the levels of GF used in this study, see e. g. Fig 1D), and across fingers. Overall, the friction was always higher in the case of the high friction material and the average relative difference was larger than $20 \%$ (paired t-test, $t(17)=10.0696, p<0.001$ ) (Fig 2B-C). Given that we aimed to observe behavioral adaption to changes in friction, we required a sufficient difference between materials and set a lower bound to a relative difference of $10 \%$. Accordingly, one participant was removed from all subsequent analyses because the relative friction difference was too low (only $2 \%$, less than the $10 \%$ required, see the unfilled dot in Fig 2B-C, participant S1 from Supp Fig 1-2). In summary, then, the two flat and transparent materials used in this study showed a consistent difference in friction, on average $23 \%$ across participants. 
A

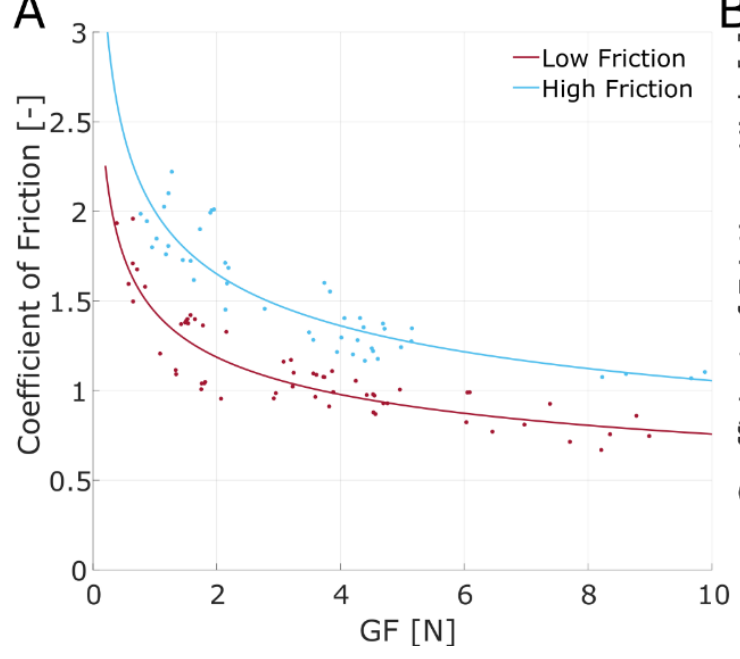

B

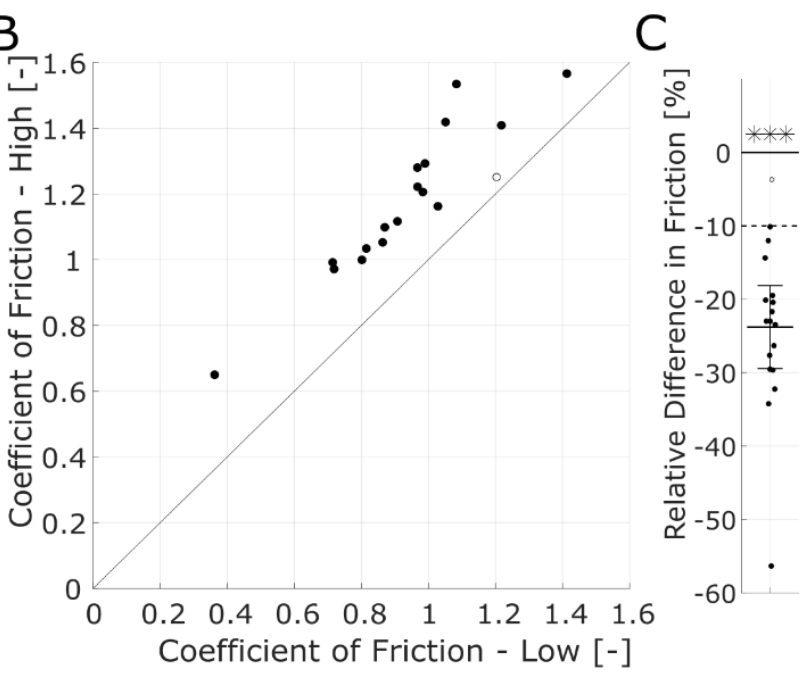

Figure 2: Consistent difference of friction. A| Coefficient of friction of the index finger as a function of grip force for a typical participant obtained using the method described in (Barrea et al. 2016). B| Mean coefficient of friction of both materials over the observed manipulation range (1-5N) for each participant $(n=18)$. $C$ l Difference in friction of the materials over the manipulation interval (1-5N), relative to the mean of the values of the coefficient of friction of both materials. The brackets show the $95 \%$ confidence interval of the mean. The dashed line indicates the level of sufficient difference in friction between materials for a participant to be included in the study. In panels $\mathrm{B} \mid$ and $\mathrm{Cl}$, one point corresponds to one individual participant and the data were averaged across both fingers and the empty circle shows the participant that was removed from the following analysis because of a difference of friction smaller than $10 \%$.

The grip force is adjusted to friction

Next, we sought to assess whether the different materials elicited different gripping behavior. First, we tested if participants could adapt to the difference in friction by using a consistently higher GF for the lower friction during the normal trials, i.e. those not following an unexpected change in friction. We found that indeed, most of the participants used a higher level of GF for the lower friction as averaged over the three static phases (Fig $3 \mathrm{~A}$ ), even though the level of GF varied widely across participants. Overall, the relative difference was statistically significant and close to $15 \%$ (Fig $3 B$, mean $14.87 \pm 12.7 \%$, paired $t$-test, $t(16)=4.8224, p<0.001)$. Thus, participants spontaneously adjusted the GF level to the friction condition. Moreover, the relative GF difference was of the same order of magnitude as the relative friction difference. We observed that the participant that was removed from the analysis because of a lack of difference in friction showed no significant difference in behavior across the friction conditions ( $\mathrm{diff}=2 \%$, as measured by the average level of GF during the static phases of normal trials). 
bioRxiv preprint doi: https://doi.org/10.1101/2021.07.20.452911; this version posted July 20, 2021. The copyright holder for this preprint (which was not certified by peer review) is the author/funder, who has granted bioRxiv a license to display the preprint in perpetuity. It is made available under aCC-BY 4.0 International license.
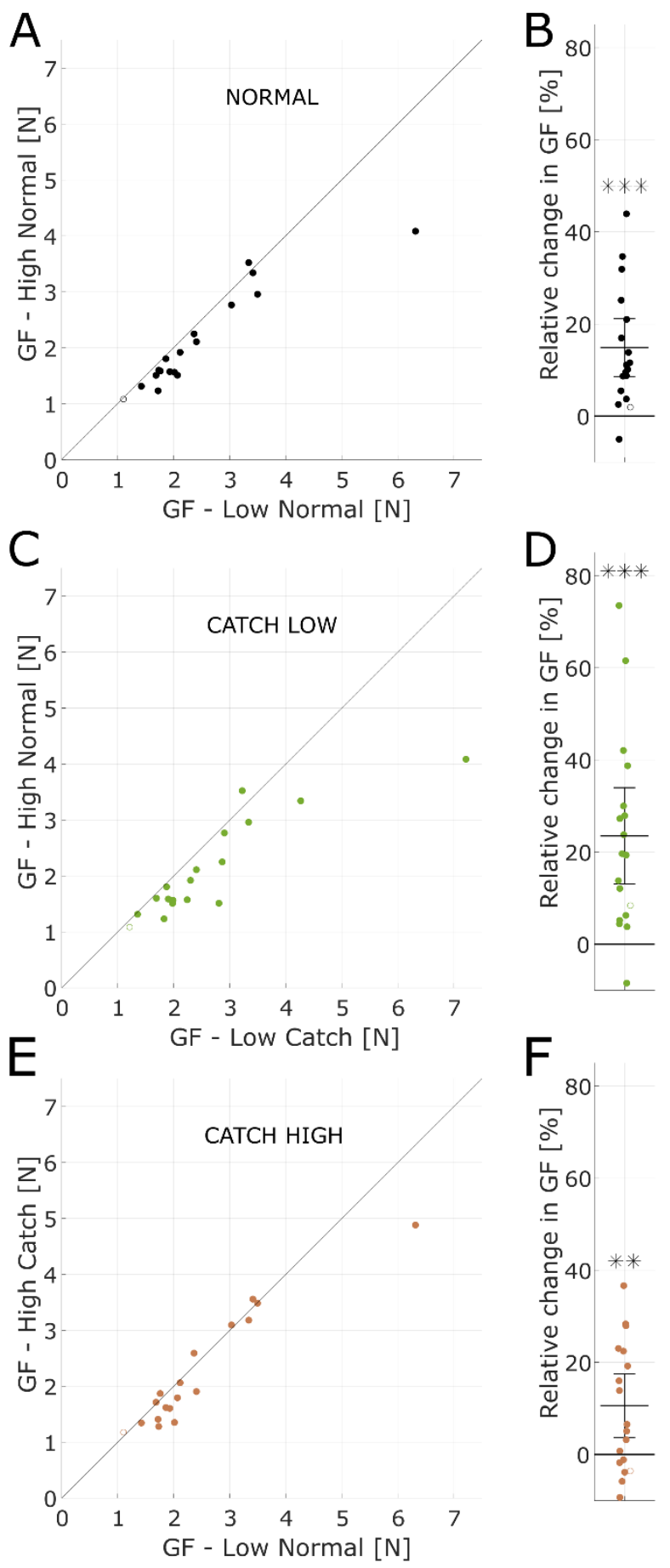

Figure 3: GF adaptation to friction during the static phases. Al Mean value of the GF for each material during the static phases of normal trials for all participants $(n=18)$. B | Change in the mean value of the GF from the high to low friction material during the static phases of normal trials, relative to the mean value of the GF in both friction conditions. The brackets show the $95 \%$ confidence interval of the mean. C, D| Same as A, B |, except the static phases of the high friction normal trials are compared to the first static phase of the low friction catch trials, which directly follow. The bar delimited with hashed lines indicates the catch trials. E, F| Same as C, D|, except the static phases of the low friction normal trials are compared to the first static phases of the high friction catch trials, which directly follow. For DI and $\mathrm{Fl}$, the percentage of change is relative to the mean of the values of normal and catch trials. The participant that is removed from the study due to a low difference of friction is shown with an empty circle and is not included in the means and confidence intervals shown. 


\section{Catch trials show GF adjustments within the first movement}

Having observed that there was indeed a GF adaptation to friction for normal trials, we then tested if a change in friction elicited a quick adjustment of the GF, as observed in the first static phase of the catch trials. To that end, we compared the static GF after the first movement (SP1, Fig 1D) of the catch trials to the static GF experienced and learned during the normal trials of the preceding block of trials associated with the material with different frictional properties. The catch trials could be of two types: (1) low friction catch trials, following an adapted exposure to high friction, were referred to as "catch-low", and (2) high friction catch trials, following an adapted exposure to low friction, were referred to as "catch-high".

\section{For the "catch-low" trials, which required an urgent increase in GF because the drop of friction} increased the risk of slip and drop of the object, we found that the GF was already higher during the first static phase (Fig $3 C$-D, paired t-test, $t(16)=4.5486, p<0.001)$ ). The adaptation was close to $20 \%$, thus already of the same magnitude as the adaptation learned throughout many trials (Fig 3B). Then, we looked at the "catch-high" trials, for which the urgency was lower since the experienced surface friction increased and therefore the risk of slippage was lower than for the directly preceding trials. We also found that the GF changed after only one movement, although the relative difference of GF was about $10 \%$ on average, thus not as large as for the catch trials in the other direction. Although this difference was not observed for all participants, it was statistically significant (Fig 3E-F, paired ttest, $\mathrm{t}(16)=3.1527, \mathrm{p}<0.01)$.

In brief, participants adapted the GF to the friction condition, and this adaptation was already present at the end of the first movement following a catch trials, and for both directions of the changes in friction.

\section{Grip force adjustments start close to the time of liftoff of catch trials}

Since we observed that the GF was already adjusted to the friction level after the first movement of catch trials, we investigated the temporal evolution of the GF during these catch trials to determine when the changes in GF evoked by the change in frictional properties arise (Figure 4). The participants produced movements with very similar kinematics across conditions, as shown by the height and LF curves, which could not be distinguished across conditions (Fig 4, top two rows of panels $A$ and $B$ ). We observed that GF curves of the catch trials progressively diverged from those of the normal trials (Fig 4A-B, third row). In these graphs, the GF were normalized according to their average values during the first static phase for each subject (values reported in Supp Fig 3).

For the "catch-low" trials (Fig 4A), we found that the GF difference reached statistical significance very early, just after liftoff ( $114 \pm 23 \mathrm{~ms}$ delay), or $50 \mathrm{~ms}$ before the peak of LF (Fig 4A, bottom row). This timing corresponded to $308 \pm 80 \mathrm{~ms}$ after initial contact. This difference was substantial, as it peaked on average at $40 \%$ with respect to GF during the first static phases of the normal trials.

For the "catch-high" trials (Fig 4B), the difference in GF reaches statistical significance later in the movement $(540 \mathrm{~ms}$ after the peak of LF, $709 \pm 20 \mathrm{~ms}$ after liftoff, and about $902 \pm 74 \mathrm{~ms}$ after initial contact) and is relatively smaller at the end of the first movement, as seen previously (Fig 3 ). Note that participants tended to apply a slightly higher level of GF at the very beginning of the contact of catch trials no matter the sign of the friction change, which might be explained by the short break between blocks. This systemic increase of the GF at the start of new blocks regardless of the actual friction condition suggests that participants were not able to anticipate the friction for the catch trials. 
bioRxiv preprint doi: https://doi.org/10.1101/2021.07.20.452911; this version posted July 20, 2021. The copyright holder for this preprint (which was not certified by peer review) is the author/funder, who has granted bioRxiv a license to display the preprint in perpetuity. It is made available under aCC-BY 4.0 International license.

In summary, we showed that GF reaches a level that is significantly different from the level of the normal trials during the first lift following a change in friction, around the time of liftoff for the "catch-low" and a bit more than half a second later for the "catch-high" trials.
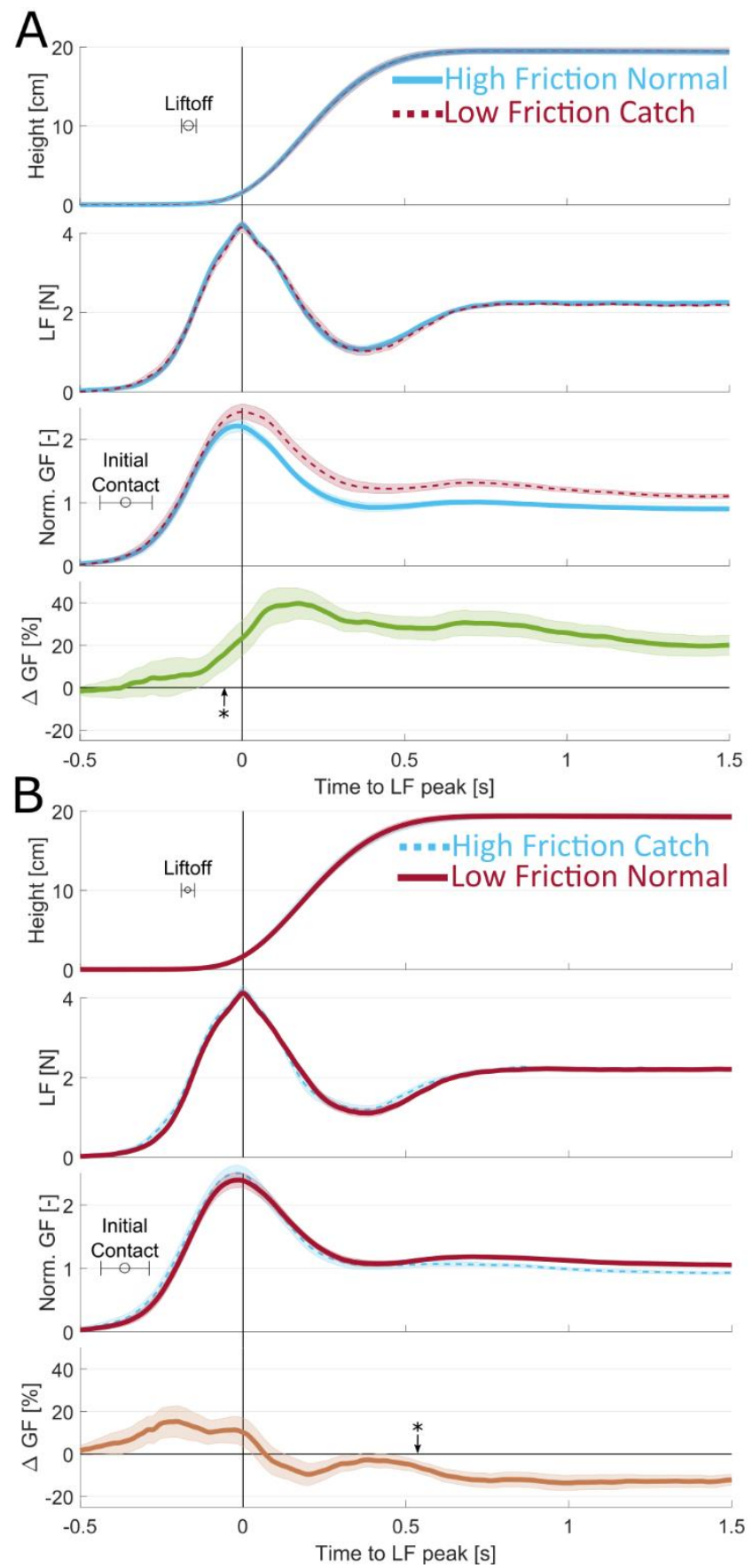

Figure 4: Adaptation to friction during the first movement of catch trials Al Evolution of object height, LF, GF, and GF difference as a function of time for the first movement of catch-down trials for all participants $(n=17)$. Trials are synchronized to the LF peak. Lines are averages across participants and shaded areas are the standard error of the mean. Os indicates the time of the maximum of Load Force. Blue is for high friction and red is for low friction. Thick continuous traces are normal trials and dashed lines are catch trials. GF normalization values are reported in Supp Fig 3. The star shows the time of the statistically significant difference between GF curves $(p<0.05)$. The lower panel shows catch minus normal trials. B| Same as A for the catch-down trials. 
bioRxiv preprint doi: https://doi.org/10.1101/2021.07.20.452911; this version posted July 20, 2021. The copyright holder for this preprint (which was not certified by peer review) is the author/funder, who has granted bioRxiv a license to display the preprint in perpetuity. It is made available under aCC-BY 4.0 International license.

\section{Subtle contrast in skin strain rate before liftoff are cues for GF adjustments} Looking at the $\Delta$ GF traces (Figure $4 A-B$, bottom rows), we can observe an upward inflection for "catch-low" trials, and a downward inflection for "catch-high" trials, happening around the LF peak and suggesting that the corrective behavior kicks in around that time. To probe the timing of the reaction of the participants to the change in friction, we thus looked at the rate of change in GF (see Fig 5A).

In Fig 5A, we first show the catch-low and catch-high $\Delta$ GF traces zoomed in a $600 \mathrm{~ms}$ time window centered on the LF peak, which appeared to be the instant of inflection of the curves. The time derivatives of those curves are also shown below in Fig 5A. Note that in this figure, in contrast to Fig 4 , we excluded the data from two participants having consistently poor image quality and we also only included the trials in which the images reached high-quality standards ( $84 \%$ of trials among the remaining participants, see Methods for more details). As observed in Fig 5A, the two $\triangle$ GF traces followed very similar trends just after contact and started to diverge around the LF peak. We found that the $\Delta$ GF rates start to diverge significantly $10 \mathrm{~ms}$ after the time of peak LF (or $370 \pm 76 \mathrm{~ms}$ after initial contact or $176 \pm 21 \mathrm{~ms}$ after liftoff), suggesting that online corrections to friction arise around this moment. Note that this is also approximately the time when the $\Delta$ GF rates become statistically significantly positive, or negative, for the "catch-low" trials, or the "catch-high" trials, both $20 \mathrm{~ms}$ after the LF peak.

The different responses of participants to catch-low and catch-high trials suggest that a sensory signal informative about the frictional properties of the material originated prior to this time. We further needed to take conduction delays into account, which for tactile-motor responses are close to $90 \mathrm{~ms}$ on average. Accordingly, we drew a grey box that encompasses the $90 \mathrm{~ms}$ before the instant of significant difference to indicate the minimal interval of time needed for the sensory feedback to reach the central nervous system and trigger a motor response (Pruszynski and Johansson, 2014; Pruszynski et al., 2016; Crevecoeur et al., 2017). Thus, to trigger a motor reaction observable just after the LF peak, a sensory signal must be readily observed before the beginning of this grey box (i.e. $80 \mathrm{~ms}$ before LF peak).

Accordingly, we evaluated the skin strain associated to partial slip during a period encompassing $300 \mathrm{~ms}$ before the LF peak until $100 \mathrm{~ms}$ after (see Supp Fig 4). In the same manner as for the GF, we report here the contrast between the catch and the normal trial, looking for a difference that might have triggered a corrective behavior. In Fig 5B, we report the differences in strain rate norm between the different conditions (catch-low, top row and catch-high bottom row), as expressed in the form of a t-value, obtained from paired t-tests performed for each pixel over the whole fingertip contact area (see Methods). Red zones show the parts of the fingertip where strain rates were significantly higher for the catch trials, i.e. where a significant excess of strain rate was observed, whereas blue zones show parts of the contact having a significantly lower strain rate for catch trials. Green zones depict insignificant differences $(t(14)<2.145$, alpha $=0.05)$. Strains were first normalized according to their average value at the time of peak LF (see methods for more details and Supp Fig 3 for normalization values). This normalization procedure was performed because subjects showed markedly different average levels of strains.

For "catch-low" trials shown in the top row of Fig 5B, a zone of excess strain rate norm in the distal part of the center of the fingertip starts appearing $250 \mathrm{~ms}$ before the maximum of $L F$ and is consistently observed until the LF peaks. This excess disappears progressively when participants start to adapt their GF to the level of friction and when the general level of strain rate becomes small. Conversely, some smaller zones in the periphery show lower levels of strain rates. Thus, surprising the participant with a material with a friction lower than for the previous trials generates a 
bioRxiv preprint doi: https://doi org/10.1101/2021.07.20.452911; this version posted July 20, 2021. The copyright holder for this preprint (which was not certified by peer review) is the author/funder, who has granted bioRxiv a license to display the preprint in perpetuity. It is made available under aCC-BY 4.0 International license.

consistently higher level of strain rates deeper inside the contact areas while leaving the periphery less strained at some places. This striking observation is valid over the span of several hundred milliseconds and can thus be taken into account by participants when adjusting their GF.

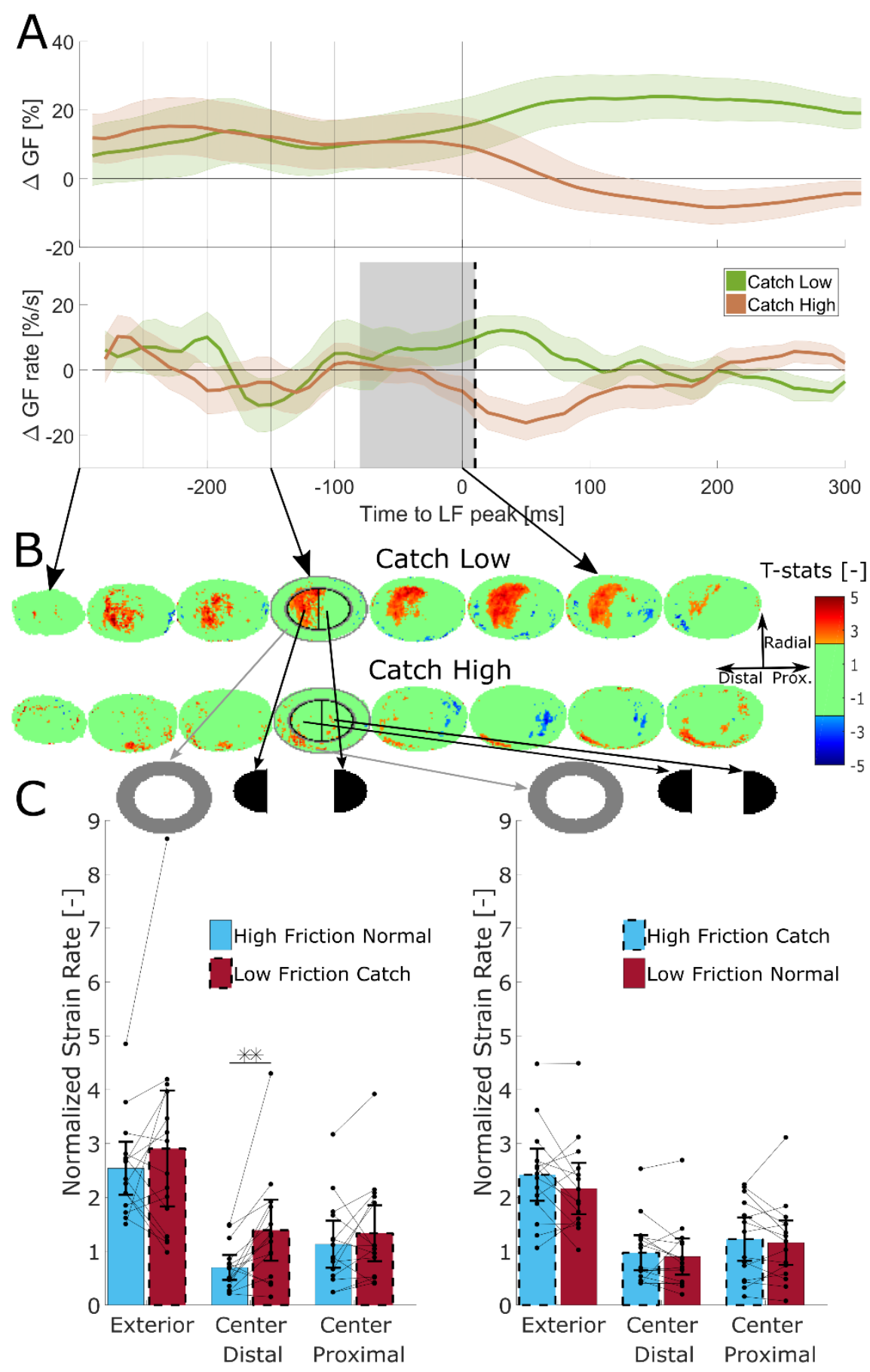

Figure 5: Differences in skin strains preceding the force adaptation $A$ | Mean difference of GF and mean difference of GF rate between catch and normal trials. Only participants for whom the images were of sufficient quality are included $(n=15)$. Oms indicates the time of the maximum of Load Force. Shaded areas are the standard error of the mean. The vertical dashed line indicates the time when the differences of Grip Force rates are statistically significantly different from each other $(10 \mathrm{~ms})$. The grey zone indicates the time during which tactile information was too close to the motor reaction to contribute to detecting the friction condition. B | Heat maps of the t-statistics of the differences in strains between catch and normal trials. The t-statistic is set to zero when the difference is not statistically significant and the corresponding $\mathrm{p}$ value is smaller than 0.05 . The red color indicates more strains in the case of the catch trial and the blue color more deformations in the case of the normal trial. The first line compares normal high friction trials to catch-low friction trials and the second line compares catch-high friction trials and normal low friction trials. Cl Average value of the strain rate norm at 
bioRxiv preprint doi: https://doi.org/10.1101/2021.07.20.452911; this version posted July 20,2021 . The copyright holder for this preprint (which was not certified by peer review) is the author/funder, who has granted bioRxiv a license to display the preprint in perpetuity. It is made available under aCC-BY 4.0 International license.

$-150 \mathrm{~ms}$ normalized w.r.t. the value at the peak of LF, in the different zones of the fingertip indicated in Fig $5 \mathrm{~B}$. The brackets show the $95 \%$ confidence interval of the mean. The bars delimited with hashed lines indicate the catch trials. One point corresponds to one individual participant.

For the "catch-high" trials shown in the bottom row of Fig 5B, we do not observe any large zone of difference in strain rate norm. Some patches in the more central part tend to show lower levels of strains rate norm. The sensory signal is less contrasted in the case of "catch-high" trials suggesting that the GF decrease might be an automatic slow decrease following a light GF excess applied because of a new block. A typical "catch-high" and "catch-low" trials are provided in the supplementary video. These show that the strain rate reaches higher level deeper in the surface of contact in the case of "catch-low" trials.

The findings are quantified in fig $5 \mathrm{C}$ where we arbitrarily defined different zones in the fingerpad, using two ellipses with the smaller one having radii $2 / 3$ as large as the larger one, and quantified the average level of strain rates for each participant at $150 \mathrm{~ms}$ before the peak of $L F$ and thus approximately $160 \mathrm{~ms}$ before the first signs of adaptation to the new friction condition. For the exterior part of the ellipse, although the level of strain rate is the highest, there is no statistically significant difference between the two conditions (paired t-test, diff $=-0.36 \pm 1.4, t(14)=-1.02$, $p=0.3257$ ). For the central proximal half part of the ellipse, the level of deformation is lower and there is still no statistically significant difference of level of strains between the two conditions (paired t-test, diff $=-0.2 \pm 0.66, t(14)=-1.12, p=0.251)$. It is only for the central distal half part of the ellipse that we observed that the amount of strain rate norm was almost twice as high for the low friction catch trials as for the normal high friction trials. This difference is large, consistent among participants and statistically significant (paired t-test, diff $=-0.69 \pm 0.8, t(14)=-3.37, p=0.0046)$. We performed the same analysis for the catch-high trials, but observed no statistically significant differences, as can be seen in the right panel of Fig $5 C$ (Exterior ellipse, paired t-test, diff $=0.26 \pm 0.62$, $t(14)=1.59, p=0.1343$. Interior proximal, paired $t$-test, diff $=0.065 \pm 0.4, t(14)=0.6, p=0.5609$. Interior distal, paired t-test, diff $=0.0705 \pm 0.35, t(14)=0.78, p=0.4497)$.

As the observed deformation contrasts take place before the grey zone defined earlier, they can contribute to the information used by the participants to adapt their GF to the condition of friction.

In summary, we observed the onset of a motor response resulting from the friction change approximately at the moment of the LF peak and this online GF correction was consistent with a sensory signal resulting from an increase in the deformations closer to the central parts for the contact area happening over $100 \mathrm{~ms}$ before the motor response. This subtle but essential sensory signal, therefore, explains GF adaptation to changes in friction.

\section{DISCUSSION}

This is, to our knowledge, the first study that quantifies how fast humans can adjust their GF to a change in friction in the case of flat transparent surfaces. We demonstrate that this adjustment can be based on a local strain pattern that takes place in the contact area with the manipulated object and signals an insecure grip. Specifically, we show that when confronted with lower friction than expected, skin strains advance deeper and faster in the contact area. The differences in skin strains with respect to a normal trial are already significant very early after the initial increase of the load force, and more than $100 \mathrm{~ms}$ before the motor response, which is a reasonable delay to explain it (Macefield and Johansson, 2003; Crevecoeur et al., 2017). These differences are present over a period of time of several hundred of milliseconds and can thus constitute a warning signal that allows the central nervous system to adjust the GF to the friction condition. 
bioRxiv preprint doi: https://doi.org/10.1101/2021.07.20.452911; this version posted July 20, 2021. The copyright holder for this preprint (which was not certified by peer review) is the author/funder, who has granted bioRxiv a license to display the preprint in perpetuity. It is made available under aCC-BY 4.0 International license.

We observed that the levels of skin strains varied greatly from participant to participant, as can be seen by the strain rates normalization values in Supp Fig 3. We have shown similar levels of variation of skin strains in a previous study where participants had to perform oscillations in a precision grip (Delhaye et al., 2021b). We can also observe in that study that a larger amount of skin strains is linked to a lower stick ratio and that the stick ratio also varied greatly between participants. The stick ratio was also measured in a study where participants had to perform a grip-lifting task (Tada et al., 2002). The authors hypothesized that humans control the level of GF to maintain a constant amount of partial slip ( $\sim 0 \%$ of the contact area) when lifting objects of known friction and weight, but they mentioned in their paper that the validness of this hypothesis has to be verified, as only three participants were tested. It is worth noting that humans perceive slippage at very different levels of partial slip in a passive setting (Barrea et al., 2018). The variability in the levels of strains and stick ratio during manipulation and the variability in partial slip between participants seem to point towards strategies of manipulation that vary from person to person. This requires further inquiring, by performing experiments with tasks of different nature, with varying friction and weight of the manipulated object. A characteristic of our results is the asymmetry of the participants' behavior between "catch-high" and "catch-low" trials (Fig 4). Although the motor reaction seemed to be triggered at the same time in both conditions (Fig 5A), it took more time to reach a level of GF that was adapted to friction in the catch-high condition. It is worth noting that a short reaction time in the catch-low condition is critical: it is urgent to increase GF since not correcting it could lead to a dramatic slip and drop of the object. In contrast, the excessive GF in the catch-high trials only results in a temporary slight excess of energy expenditure, which does not require to act quickly. The difference in urgency to adapt GF between conditions is observed in the differences of strains (Fig 5 $B-C)$, where a surprisingly low level of friction caused significant differences in strains whereas a surprisingly high level of friction did not.

Although we characterized the friction between the fingers and the manipulated object by a constant scalar value per participant-condition pair (Fig 2B-C), this is clearly a gross approximation of a very complex phenomenon. The tribology of the skin is complex and varies significantly at different temporal and spatial scales (Pataky et al., 2005; Adams et al., 2013; Van Kuilenburg et al., 2015). One aspect of this complexity is related to the complex geometry and mechanics of the finger: the fingertips are composed of several layers, from the bone in the interior of the fingertip to the epidermis in the exterior. The epidermis of the glabrous skin is characterized by the presence of ridges and furrows that form the fingerprints and present a complex topography (Choi et al., 2021). This complex geometry and mechanics is likely to impact the friction on a trial to trial basis, depending on how the finger contacts the object. Another aspect of the complex tribology of the skin is that it evolves over time: Sweat pores are present at the surface of the skin and produces humidity at the interface that heavily impacts the level of friction when gripping a material, which changes over the course of several seconds (André et al., 2010; Yum et al., 2020). The occlusion phenomenon defines humidity evolution and plasticization of the skin when in close contact with the material for a few seconds (Adams et al., 2013). The level of friction thus varies during a single trial as moisture varies due to occlusion. In our experiment, the moisture level is however probably partially maintained when trials are close enough from one another. Thus, in the context of this study, the differences in friction measured between materials, which could vary widely between participants, are to be considered as approximations of their actual values, which can vary during manipulation. However, it is clear that the difference in friction between materials was consistent and sufficient to generate coherent adaptation of GF during the overall experiment.

Several of our senses are used when performing a task as difficult as fine object manipulation. Our sense of touch in particular is very important. It sends critical information to the central nervous 
system to adjust GFs to various parameters of the manipulation such as friction. We have shown that when gripping and lifting small objects, the skin strains depended on the level of friction at the interface of the contact. The localized differences in skin strains between conditions during the loading phase were consistent with the timing of the first signs of adaptation of the GF and were sufficient to explain them. We have quantified and described those skin strains and measured the GF modulation, which started less than $500 \mathrm{~ms}$ after the initial contact.

\section{METHODS}

\section{Participants}

Eighteen volunteers ( 5 females; ages 20-65) participated in the experiment. All of them provided written informed consent to the procedures and the study was approved by the ethics committee at the host institution (UCLouvain, Brussels, Belgium).

\section{Apparatus}

At rest, the device was standing on a table with a hole to allow the passage of the cables coming from the bottom of the device. Its weight $(540 \mathrm{~g})$ was partially compensated by a counterweight $(320 \mathrm{~g})$ attached to a system of pulleys. The device is described at length in a recent publication(Delhaye et al., 2021b). Succinctly, forces were measured under each fingertip using two six-axis force and torque sensors (ATI Mini27 Ti, ATI-IA, Apex, NC, USA). From those measurements, the GF and LF were computed, as described in Data Analysis. The position was measured using an optical distance sensor (DT20-P224B, SICK Sensor Intelligence). The position and forces were sampled at 200 Hertz with a NI-DAQ card (NI6225, National Instruments).

A custom optical system allowed to image the index fingerprints in contact with the glass (Fig 1F). Because of constraints in the design of the manipulandum, it was only possible to monitor one side, as the light is emitted by an array from the side where the thumb is, blocking its observation. This system is based on the principle of Frustrated Total Internal Reflection and enables a high contrast between the point in contact with the glass and those that are not. Images are recorded at $100 \mathrm{fps}$ with a camera (GO-5000M-PMCL, JAI, monochrome, $2560 \times 2048$ full pixel resolution). Image size is $1696 \times 1248$ pixels with a resolution of 4096 pixels $/ \mathrm{mm}^{2}$, which corresponds to an area of $26.5 \mathrm{x}$ $19.5 \mathrm{~mm}$.

Two kinds of glass plates were used to generate different levels of friction. The first set of plates are simple transparent optically flat plates of glass. They are referred to as "high friction". A process called "glass frosting" was used to alter friction in the second set of plates. In brief, a chemical process was used to imprint a nanoscale pattern on the surface of the glass. With the right set of parameters (height and roughness), this decreased the real area of contact between the finger and the plate and thus the coefficient of friction (Derler et al., 2009; Skedung et al., 2010, 2011; Adams et al., 2013; Wiertlewski et al., 2016; Inamoto and Tomeno, 2019). This nano-structured glass was referred to as the "low-friction" surface. The transparent plates are indistinguishable to the naked eye.

\section{Experimental procedures}

Participants stood in front of a table on which the device was positioned. After an auditory cue, they were instructed to grip and lift the device to a height of about $20 \mathrm{~cm}$ within $0.8 \mathrm{~s}$, and then hold it still for $1.5 \mathrm{~s}$. They then performed three fast point-to-point movements $(0.8 \mathrm{~s})$ with pauses $(1.5 \mathrm{~s})$ inbetween. Auditory cues were used to pace each movement. We observed that participants' movements were slightly slower than what was instructed, resulting in slightly longer movements and shorter static phases. The participants were requested (and often reminded during the 
experiment) to use a minimal amount of GF. Indeed, we observed in a preliminary study that participants tended to use an excessive amount of GF naturally, probably because this device composed of a camera and sensors seems fragile and looks heavy. The glass plates were cleaned with alcohol after each trial. This served the purpose of getting images as clean as possible. Also, this procedure removed sweat that could alter the topography of the glass plates at a microscopic level and thus the level of friction. After each block of five trials, participants were instructed to take a break on the other side of the room, from a location where they could not see the experimenter manipulating the device. During that break, the experimenter interchanged the plates such that the friction was changed from high to low or from low to high. This procedure was quick and took a maximum of 2 minutes. Half of the participants started with the high friction condition and the other half with the low friction. This caused no difference in their adaptation to friction, as measured by the difference in GF between conditions during the first static phase of normal trials (t-test, $t(15)=0.36, p=0.72$ ). The coefficient of friction was measured for each material at the end of the experiment (see Friction Measurement). In total, the experiment lasted between one and a half and two hours for each participant.

Friction measurements. We measured the coefficient of friction between the participants' fingers and both materials at the end of the experiment using the method described in (Barrea et al., 2016). Briefly, participants were instructed to rub their index finger and thumb on the glass plates for three periods of fifteen seconds at different levels of normal forces. The approximate range of normal forces for each period was 0 to $2.5 \mathrm{~N}$ for the first, 2.5 to $6 \mathrm{~N}$ for the second, and 6 to $10 \mathrm{~N}$ for the third. The moment of slippage was detected by finding the maximum of the ratio of tangential force over normal force at the start of each rubbing motion. This ratio was measured and was our estimation for the static coefficient of friction corresponding to the normal force applied at that moment. The data were obtained for both fingers of all participants (see Supp Fig 1-2) and fit with a negative power law (André et al., 2009). From the fits, we computed a single coefficient of friction value for each participant and each material for the $1-5 \mathrm{~N}$ range that corresponded to the approximate range that the participants used for manipulation. The friction was averaged across both fingers. The measurement of the friction was always performed first on the material with which the participant finished the experiment.

\section{Data analysis}

Forces and position data were filtered with a fourth-order low-pass Butterworth filter with a cut-off frequency of $40 \mathrm{~Hz}$. The $\mathrm{GF}$ is defined as the mean of the norm of the forces normal to the surface of the object exerted by each finger. The LF is defined as the norm of the sum of the forces applied tangentially to both surfaces by each finger. When comparing dynamics or kinematics between participants as in Fig 3, 4 and 5, an average curve was first computed for each participant by first synchronizing all trials on the maximum of LF for each separate movement. Then, statistics such as the inter-subject mean or standard error of the mean were computed based on these average curves.

GF normalization. As participants typically used different levels of GF, a normalization procedure was used when comparing the GF signals across conditions and participants. A GF normalization value was obtained for each participant by taking the mean of GF during the first static phases of all normal trials (except the first two blocks that were excluded because of the learning period). They are shown in Supp Fig 3.

Image processing. A previously described image processing pipeline was used to evaluate the skin strains from the raw images (see Delhaye et al, 2014, 2016). This pipeline is only summarized here. First, a custom-made machine learning algorithm was used to detect the area of contact between the 
finger and the glass plate for each image. This algorithm was trained for each participant separately with manually detected areas of contact for randomly selected images. Then, feature points were selected automatically from several frames of the sequences of images (at the beginning, during, and at the end of each movement). Their position was tracked forward and backward in time from frame to frame using an algorithm of optical flow (Lucas and Kanade, 1981; Shi and Tomasi, 1994). A Delaunay triangulation was then computed and the evolution of the shape of the triangles allowed to measure the local strain rate along three dimensions (vertical, horizontal, and shear strain rate). The norm of the strain rate was calculated as follows:

$$
\varepsilon_{n}=\left\|\begin{array}{ll}
\varepsilon_{x x} & \varepsilon_{x y} \\
\varepsilon_{x y} & \varepsilon_{y y}
\end{array}\right\|=\sqrt{\varepsilon_{x x}^{2}+\varepsilon_{y y}^{2}+2 \varepsilon_{x y}^{2}}
$$

where $\varepsilon_{x x}, \varepsilon_{y y}$ and $\varepsilon_{x y}$ are the horizontal, vertical, and shear strains rates components respectively. This gave a quantitative measure of how the different parts of the fingertips were being deformed, irrespective of the type and directions of these deformations. In this study, we were mostly interested in comparing the amount of strain rate according to the condition of friction and the adaptation of GF rather than the specific description of these deformations(Delhaye et al., 2021b).

As different participants showed markedly different levels of strains, we normalized the strain rate norm of each participant by the mean value of the strain rate norm across the entire area of contact and trials at the time of maximum LF. The normalization values of the strain rate norm are given together with the normalization value of the GF for each participant in Supp Fig 3.

The first images of the contact were difficult to interpret. Indeed, the fingertip skin can be rough and stiff on a small scale, depending on the moisture content of the individual's skin. When it enters in contact with a stiff surface such as glass, the initial real area of contact is low. However, during the first tens of milliseconds of the contact, moisture secreted by the sweat pores hydrates the skin, rendering it softer and elasticizing it. The skin then enters in closer contact with the surface and the real area of contact increases (Pasumarty et al., 2011; Bochereau et al., 2017; Dzidek et al., 2017). As a rapidly changing real contact area not associated with skin deformations was problematic for the interpretation of the results of our image-processing pipeline, we decided to discard the images directly following the time of contact between the skin and the surface from our analysis. We used the first image of the loading phase, defined as the moment when a participant starts applying tangential force to lift the object after the pre-loading phase (Westling and Johansson, 1984) as the first image in our image processing pipeline. This guaranteed that the apparition of moisture would only play a negligible role in our measurement of strains and that the strains caused by the vertical lifting of the object would be included in our analysis.

Strain rate summary across participants. To get a summary of strain rates across trials and participants, we first had to project the values from the triangulation used to compute the strains to a standardized structured grid common for all participants. To that end, we first created a reference ellipse with a major to minor axes radii ratio of $3 / 2$. A gridded mesh of size $91 \times 61$ was attached to this reference ellipse. Then a least-square procedure was used to fit ellipses on the coordinates of the fingerprint contact area contour for all individual images (Fitzgibbon et al., 1999). Finally, we computed the projection (offset, scaling, and rotation) from the ellipse obtained from the image at the instant of the LF peak to the reference ellipse for each trial and movement. This projection, obtained for each trial and movement, was applied to the center of each triangle for all images to obtain strains on the reference ellipse. The maximum of LF was chosen to compute the projection because this timestamp is used to synchronize the trials. At that instant, the area of contact between the finger and the glass has already plateaued. After having applied this projection, the strain rate norm was averaged for each participant and each condition (i.e. catch/normal and low/high friction). 
An example of such data for a typical participant is presented in Supp Fig 4. Subsequent statistics on strains across participants were performed on the projected data.

Inspection and sorting of trials. As mentioned in Results, the first two blocks were considered to be "training blocks" as the participants' GFs decreased significantly during those for all participants and were thus excluded from the data analysis (Fig 1C). The third block was the first included in our analysis because it was the first for which (1) the grip forces were on average smaller than in the next one in the high friction condition and (2) the grip forces were larger than in the next one in the low friction condition. For some trials, participants placed their index finger outside of the field of the camera or displaced it outside of the field during the trial due to slipping or rolling. Some trials were therefore not included in the analysis. Only the parts of the trials where the finger got out of the field of the camera were removed. After a close inspection of each trial, 99 out of 720 were at least partly removed because the images were unusable during some part of the trial. Those trials were still used for the kinematics and dynamics analysis of Fig 2-4. Also, 15 participants were used for the image and forces analyses of Fig 5 because two participants had very dry skin and the image quality was insufficient to obtain reliable strain data.

Full slip trials. To get a different look at our data, we counted the proportion of trials for which a full slip occurred during the first movement, which yielded the following results: a full slip occurred in $11.33 \%$ of the high friction normal trials, $12.75 \%$ of the low friction normal trials, $11.77 \%$ of high friction catch trials, and $31.03 \%$ of low friction catch trials. A full slip is said to occur when all the feature points whose positions are tracked from frame to frame are measured as moving with respect to the glass. This result is consistent with the differences in strain that are shown in Fig $5 \mathrm{~B}$ and $\mathrm{C}$. That is, in some cases, the strain wave reached the central point of the contact. Note that even if full slip occurred for some trials, the extent of slippage was small and was quickly stopped by a corrective GF (slipping distance of the central part of the contact area of $0.19 \pm 0.25 \mathrm{~mm}$, mean \pm std, for trials in which the full slip was reached). The full slip trials were included in the strain analysis like all other trials.

\section{Statistical analysis}

All statistical analyses were performed with MATLAB, using the functions corr (for Pearson correlation), ttest (for paired t-tests), and tinv (inverse of Student's T cumulative distribution function). The test performed, the number of degrees of freedom, and the T-statistics are always mentioned with the $p$-value. The $95 \%$ confidence interval of the means were computed using one mean value per participant and using the following formula:

$$
C I=\bar{X} \pm Z \frac{s}{\sqrt{n}}
$$
T cumulative distribution function (e.g. $Z=2.12$ for 17 participants), $s$ is the standard deviation and $n$ is the number of participants. 


\section{REFERENCES}

Adams MJ, Johnson SA, Lefèvre $P$, Lévesque V, Hayward V, Adams MJ, Johnson SA, Lefe $P$, Thonnard $\mathrm{JL}$, Hayward V, Andre T, André T, Thonnard JL, Levesque V. 2013. Finger pad friction and its role in grip and touch. J R Soc Interface 10:20120467. doi:10.1098/rsif.2012.0467

André T, Lefèvre $P$, Thonnard J. 2010. Fingertip moisture is optimally modulated during object manipulation. J Neurophysiol 103:402-408. doi:10.1152/jn.00901.2009

André T, Lévesque V, Hayward V, Lefèvre $P$, Thonnard J. 2011. Effect of skin hydration on the dynamics of fingertip gripping contact. $J R$ Soc Interface 8:1574-1583. doi:10.1098/rsif.2011.0086

Augurelle A-S, Smith AM, Lejeune T, Thonnard J. 2003. Importance of cutaneous feedback in maintaining a secure grip during manipulation of hand-held objects. J Neurophysiol 89:665-671. doi:10.1152/jn.00249.2002

Barrea A, Cordova Bulens D, Lefevre P, Thonnard J-L. 2016. Simple and Reliable Method to Estimate the Fingertip Static Coefficient of Friction in Precision Grip. IEEE Trans Haptics 9:492-498. doi:10.1109/TOH.2016.2609921

Barrea A, Delhaye BP, Lefèvre P, Thonnard J-L. 2018. Perception of partial slips under tangential loading of the fingertip. Sci Rep 8:7032. doi:10.1038/s41598-018-25226-w

Birznieks I, Burstedt MK, Edin BB, Johansson RS. 1998. Mechanisms for force adjustments to unpredictable frictional changes at individual digits during two-fingered manipulation. $J$ Neurophysiol 80:1989-2002.

Bochereau S, Dzidek B, Adams M, Hayward V. 2017. Characterizing and Imaging Gross and Real Finger Contacts under Dynamic Loading. IEEE Trans Haptics 10:456-465. doi:10.1109/TOH.2017.2686849

Cadoret G, Smith AM. 1996. Friction, not texture, dictates grip forces used during object manipulation. J Neurophysiol 75:1963-9.

Choi C, Ma Y, Li X, Ma X, Hipwell MC. 2021. Finger Pad Topography beyond Fingerprints: Understanding the Heterogeneity Effect of Finger Topography for Human-Machine Interface Modeling. ACS Appl Mater Interfaces 13:3303-3310. doi:10.1021/acsami.0c15827

Crevecoeur F, Barrea A, Libouton X, Thonnard J, Lefèvre P. 2017. Multisensory components of rapid motor responses to fingertip loading. J Neurophysio/ 118:331-343. doi:10.1152/jn.00091.2017

Delhaye BP, Barrea A, Edin BB, Lefèvre P, Thonnard J-L. 2016. Surface strain measurements of fingertip skin under shearing. J $R$ Soc Interface 13:20150874. doi:10.1098/rsif.2015.0874

Delhaye BP, Jarocka E, Barrea A, Thonnard J-L, Edin BB, Lefèvre P. 2021a. High-resolution imaging of skin deformation shows that afferents from human fingertips signal slip onset. Elife.

Delhaye BP, Lefèvre $P$, Thonnard J-L. 2014. Dynamics of fingertip contact during the onset of tangential slip. J R Soc Interface 11:20140698. doi:10.1098/rsif.2014.0698

Delhaye BP, Long KH, Bensmaia SJ. 2018. Neural Basis of Touch and Proprioception in Primate CortexComprehensive Physiology. Hoboken, NJ, USA, NJ, USA: John Wiley \& Sons, Inc. pp. 1575-1602. doi:10.1002/cphy.c170033

Delhaye BP, Schiltz F, Barrea A, Thonnard J-L, Lefèvre P. 2021b. Measuring fingerpad deformation during active object manipulation. bioRxiv. 
Derler S, Gerhardt L-C, Lenz a., Bertaux E, Hadad M. 2009. Friction of human skin against smooth and rough glass as a function of the contact pressure. Tribol Int 42:1565-1574. doi:10.1016/j.triboint.2008.11.009

Dzidek B, Bochereau S, Johnson SA, Hayward V, Adams MJ. 2017. Why pens have rubbery grips. Proc Natl Acad Sci 201706233. doi:10.1073/pnas.1706233114

Farajian M, Leib R, Kossowsky H, Zaidenberg T, Mussa-Ivaldi FA, Nisky I, Vaadia E. 2020. Stretching the skin immediately enhances perceived stiffness and gradually enhances the predictive control of grip force. Elife 9:1-38. doi:10.7554/eLife.52653

Inamoto M, Tomeno S. 2019. Tactile feel designed glassIEEE World Haptics Conference.

Johansson RS, Flanagan JR. 2009. Coding and use of tactile signals from the fingertips in object manipulation tasks. Nat Rev Neurosci 10:345-359. doi:10.1038/nrn2621

Johansson RS, Westling G. 1984. Roles of glabrous skin receptors and sensorimotor memory in automatic control of precision grip when lifting rougher or more slippery objects. Exp Brain Res 56:550-564. doi:10.1007/BF00237997

Khamis H, Redmond SJ, Macefield V, Birznieks I. 2014. Classification of Texture and Frictional Condition at Initial Contact by Tactile Afferent ResponsesHaptics: Neuroscience, Devices, Modeling, and Applications. pp. 460-468. doi:10.1007/978-3-662-44193-0_58

Levesque V. 2002. Measurement of skin deformation using fingerprint feature tracking.

Lucas B, Kanade T. 1981. An iterative image registration technique with an application to stereo vision. IJCAI 130:121-130.

Macefield VG, Johansson RS. 2003. Loads applied tangential to a fingertip during an object restraint task can trigger short-latency as well as long-latency EMG responses in hand muscles. Exp brain Res 152:143-9. doi:10.1007/s00221-003-1421-9

Nowak DA, Hermsdörfer J, Glasauer S, Philipp J, Meyer L, Mai N. 2001. The effects of digital anaesthesia on predictive grip force adjustments during vertical movements of a grasped object. Eur J Neurosci 14:756-762. doi:10.1046/j.0953-816X.2001.01697.x

Pasumarty SM, Johnson SA, Watson SA, Adams MJ. 2011. Friction of the human finger pad: Influence of moisture, occlusion and velocity. Tribol Lett 44:117-137. doi:10.1007/s11249-011-9828-0

Pataky TC, Latash ML, Zatsiorsky VM. 2005. Viscoelastic response of the finger pad to incremental tangential displacements. J Biomech 38:1441-9. doi:10.1016/j.jbiomech.2004.07.004

Pruszynski JA, Johansson RS. 2014. Edge-orientation processing in first-order tactile neurons. Nat Neurosci 17:1404-1409. doi:10.1038/nn.3804

Pruszynski JA, Johansson RS, Flanagan JR. 2016. A Rapid Tactile-Motor Reflex Automatically Guides Reaching toward Handheld Objects. Curr Bio/ 26:788-792. doi:10.1016/j.cub.2016.01.027

Shi J, Tomasi C. 1994. Good features to trackProceedings of IEEE Conference on Computer Vision and Pattern Recognition CVPR-94. IEEE Comput. Soc. Press. pp. 593-600. doi:10.1109/CVPR.1994.323794

Skedung L, Danerlöv K, Olofsson U, Aikala M, Niemi K, Kettle J, Rutland MW. 2010. Finger Friction Measurements on Coated and Uncoated Printing Papers. Tribol Lett 37:389-399. doi:10.1007/s11249-009-9538-z

Skedung L, Danerlöv K, Olofsson U, Michael Johannesson C, Aikala M, Kettle J, Arvidsson M, Berglund $B$, Rutland MW. 2011. Tactile perception: Finger friction, surface roughness and perceived 
bioRxiv preprint doi: https://doi.org/10.1101/2021.07.20.452911 this version posted July 20.2021. The copyriaht holder for this preprin (which was not certified by peer review) is the author/funder, who has granted bioRxiv a license to display the preprint in perpetuity. It is made available under aCC-BY 4.0 International license.

683

coarseness. Tribol Int 44:505-512. doi:10.1016/j.triboint.2010.04.010

Tada M, Mochimaru M, Kanade T. 2006. How does a fingertip slip? - Visualizing partial slippage for modeling of contact mechanics. Eurohaptics 2006 2-7.

Tada M, Shibata T, Ogasawara T. 2002. Investigation of the touch processing model in human grasping based on the stick ratio within a fingertip contact interface. IEEE Int Conf Syst Man Cybern vol.5:6. doi:10.1109/ICSMC.2002.1176358

Van Kuilenburg J, Masen MA, Van Der Heide E. 2015. A review of fingerpad contact mechanics and friction and how this affects tactile perception. Proc Inst Mech Eng Part J J Eng Tribol. doi:10.1177/1350650113504908

Westling G, Johansson RS. 1987. Responses in glabrous skin mechanoreceptors during precision grip in humans. Exp Brain Res 66:128-140. doi:10.1007/BF00236209

Westling G, Johansson RS. 1984. Factors influencing the force control during precision grip. Exp brain Res 53:277-84.

Wiertlewski M, Fenton Friesen R, Colgate JE. 2016. Partial squeeze film levitation modulates fingertip friction. Proc Natl Acad Sci 201603908. doi:10.1073/pnas.1603908113

Witney AG, Wing A, Thonnard J-L, Smith AM. 2004. The cutaneous contribution to adaptive precision grip. Trends Neurosci 27:637-643. doi:10.1016/j.tins.2004.08.006

Yum S-M, Baek I-K, Hong D, Kim J, Jung K, Kim Seontae, Eom K, Jang J, Kim Seonmyeong, Sattorov M, Lee M-G, Kim Sungwan, Adams MJ, Park G-S. 2020. Fingerprint ridges allow primates to regulate grip. Proc Natl Acad Sci 117:31665-31673. doi:10.1073/pnas.2001055117 
bioRxiv preprint doi: https://doi.org/10.1101/2021.07.20.452911; this version posted July 20, 2021. The copyright holder for this preprin (which was not certified by peer review) is the author/funder, who has granted bioRxiv a license to display the preprint in perpetuity. It is made available under aCC-BY 4.0 International license.
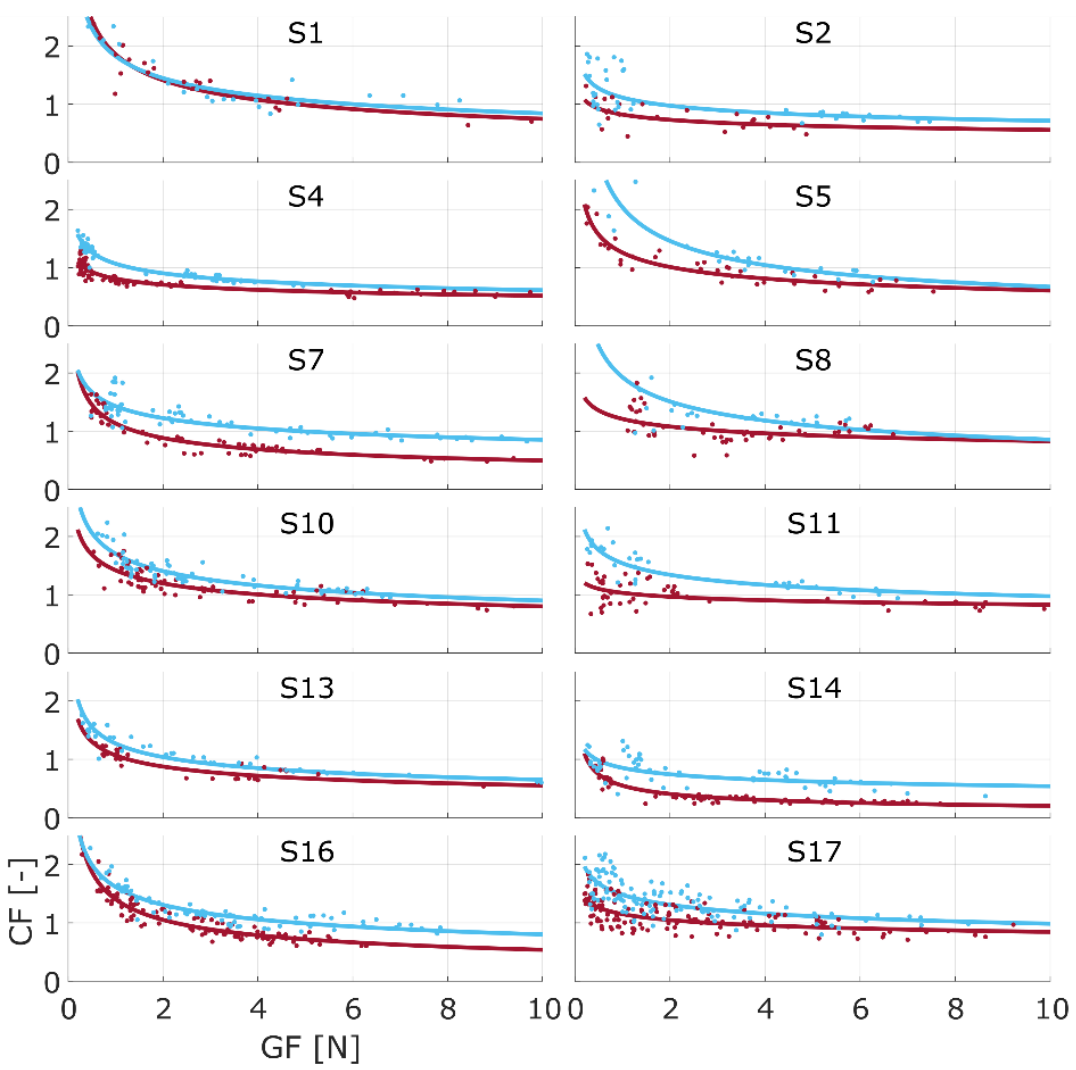
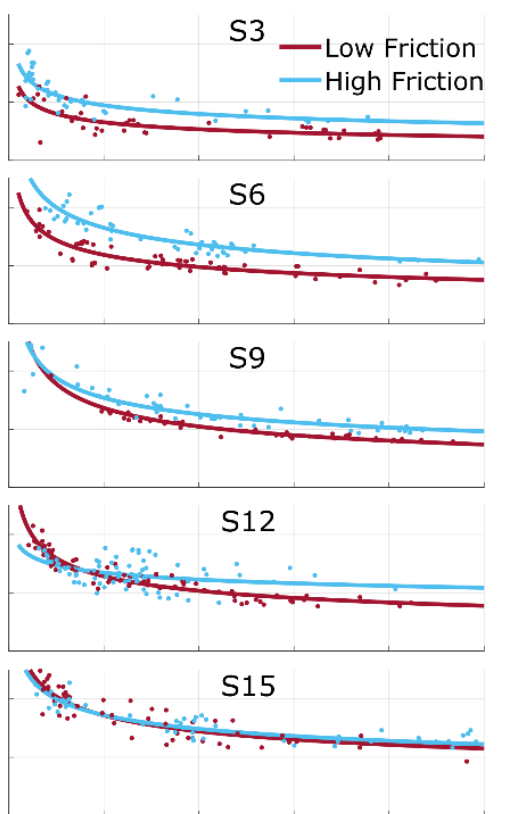

$\mathrm{S} 18$

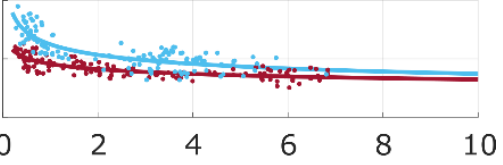

Supp. Figure 1: Coefficient of friction of the index finger for all participants
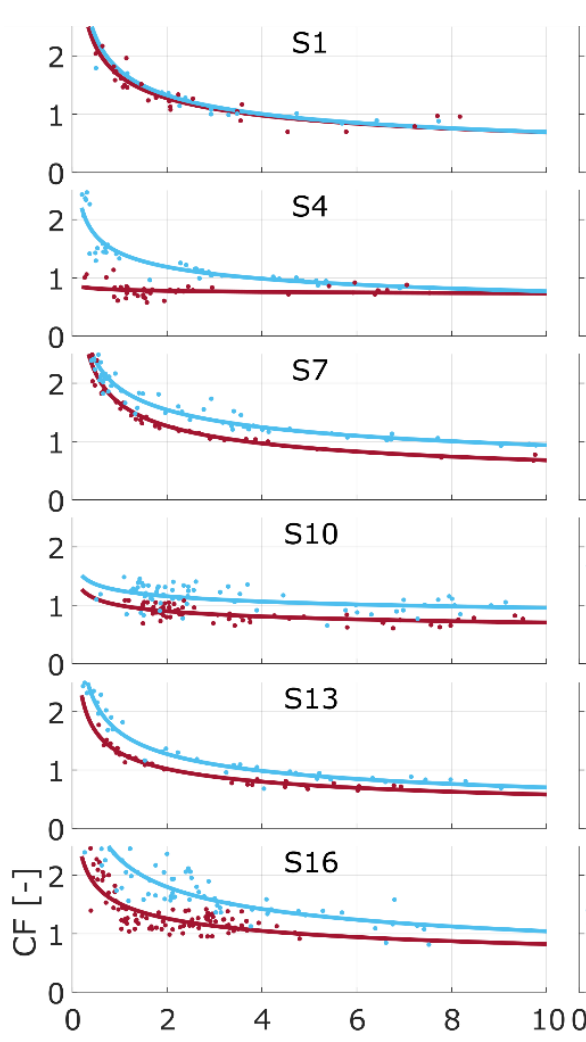
GF $[N]$
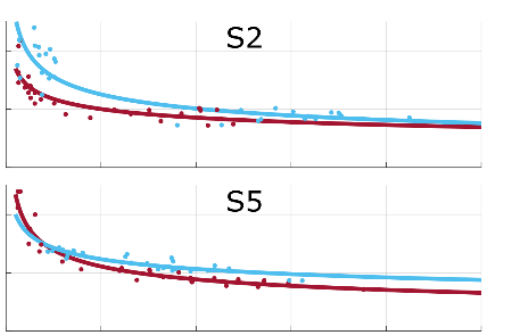

S8

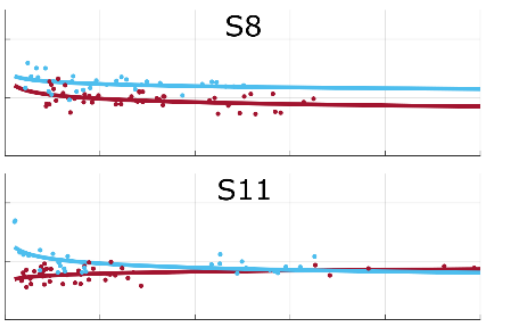

S14

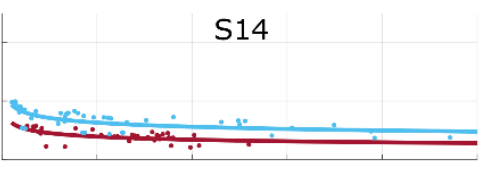

$\mathrm{S} 17$

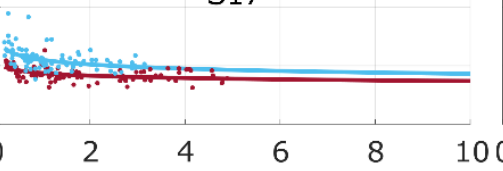

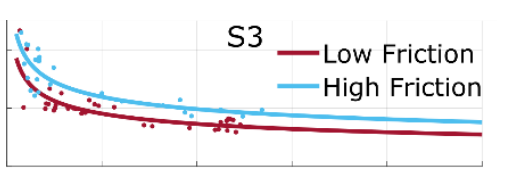
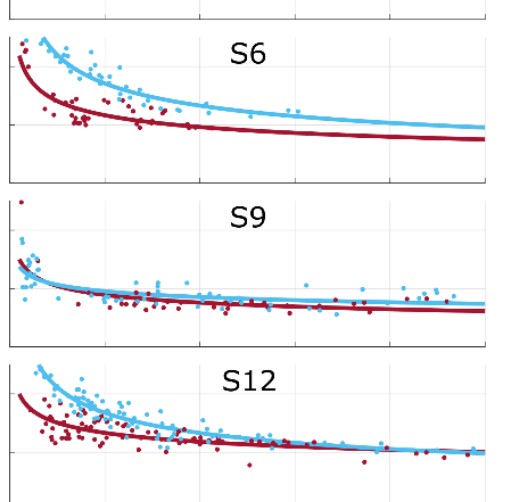

S15

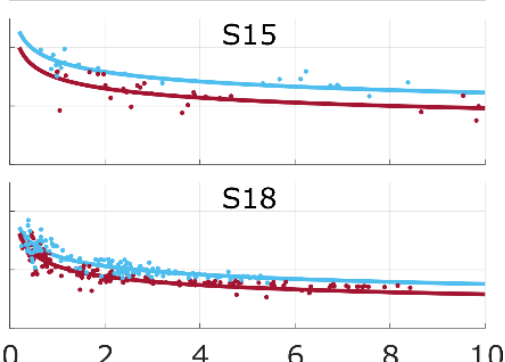

687

Supp. Figure 2: Coefficient of friction of the thumb for all participants 
bioRxiv preprint doi: https://doi.org/10.1101/2021.07.20.452911; this version posted July 20, 2021. The copyright holder for this preprint (which was not certified by peer review) is the author/funder, who has granted bioRxiv a license to display the preprint in perpetuity. It is made available under aCC-BY 4.0 International license.

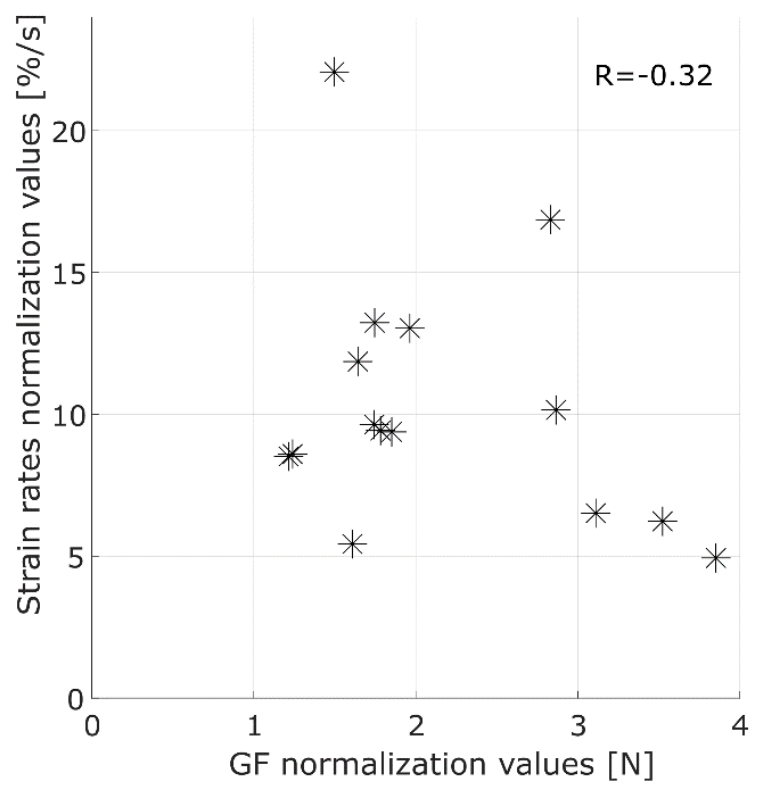

690 Supp. Figure 3: Normalization values for the GF and strains

691

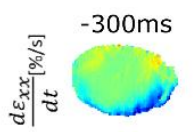

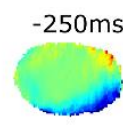
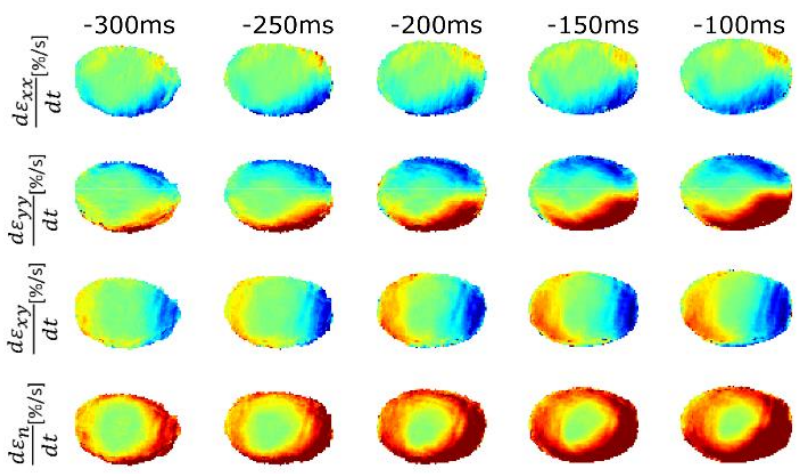
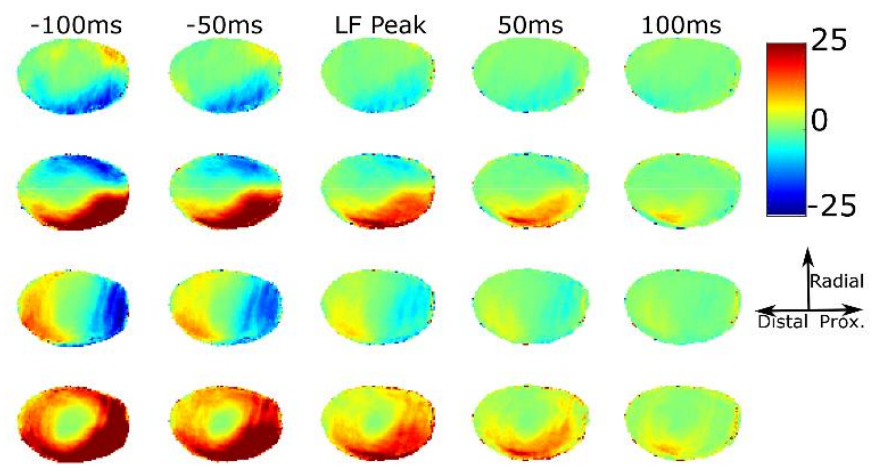

Supp. Figure 4: Averaged strain rate data on the standard grid during the first movement for a typical participant. Compression is shown in red and dilation in blue. The first row shows the horizontal strain rate, the second shows the vertical strain rate, the third shows the shear strain rate and the fourth shows the strain rate norm. The average was 